\title{
MARINE BIODIVERSITY IN SPACE AND TIME WHAT TINY FOSSILS TELL
}

\author{
MORIAKI YASUHARA
}

\begin{abstract}
Biodiversity has been changing both in space and time. For example, we have more species in the tropics and less species in the Arctic and Antarctic regions, constituting the latitudinal diversity gradient, one of the patterns we can see most consistently in this complex world. We know much less regarding the biodiversity gradients with time. This is because it would require a well designed continuous monitoring program, which seldom persist beyond a few decades. But, luckily, we have remains of ancient organisms, called fossils. These are basically the only direct records of past biodiversity.
\end{abstract}

Keywords: microfossils, ecology, evolution, paleontology, biogeography.

\section{BEAUTIFUL AND USEFUL TINY FOSSILS}

Some organisms have extraordinary fossil records. Especially small organisms called microfossils (microscopic-sized fossils) allow us to infer past biodiversity patterns in detail, because tens of thousands of them can be collected from just a handful of sediments and rocks (Yasuhara, Tittensor, Hillebrand, \& Worm, 2017). For example, we know latitudinal diversity gradient of various marine organisms (Figure 1) (Hillebrand, 2004), but it is not easy to know how the past gradient was, because, for example, fishes (or most other organisms) are rarely preserved as fossils. By using a microfossil group, planktonic foraminifera (Figure 2), we can look into past biodiversity and its latitudinal gradient of the pelagic ocean.

Planktonic foraminifera (shelled protozoans typically between 0.1 and $1 \mathrm{~mm}$ in size) may not be popular but they are very important microfossils because of the following reasons. In the first place, billions of them preserved in sediments and rocks record geological and paleontological history almost perfectly. Secondly, almost all Cenozoic species are formally described, standardized indentifications are well established because of their importance in biostratigraphy and paleoceanography, and the number of species is manageable (i.e., not too numerous: around 40 species of this plankton are known in the present-day oceans in total), in other words, their taxonomy is robust (Yasuhara, Hunt, Dowsett, Robinson, \& Stoll, 2012; Yasuhara, Tittensor, et al., 2017). By comparing the latitudinal diversity patterns between the present day and the last ice age (20,000 years ago), we see persistence of the gradient from tropics to poles (Yasuhara et al., 2012) (Figure 3). But, by looking into the details, it is clear that the ice age diversity gradient is much steeper than the presentday one. Although tropical diversities are similar between the last ice age and the present day, the ice-age and present-day diversities start to diverge from $20-30^{\circ} \mathrm{N}$ toward higher latitudes (Figure 3a). Why? If we compare diversities not only with latitudes but also with ocean temperature, we see a plausible answer. The ocean's surface temperature of the last ice age is well known based on various micropaleontological and geochemical methods (Yasuhara et al., 2012). The relationship between temperature and diversity is surprisingly consistent between the present day and the last ice age (Figure 3b). So, the latitudinal diversity gradient was steeper during the last ice age 


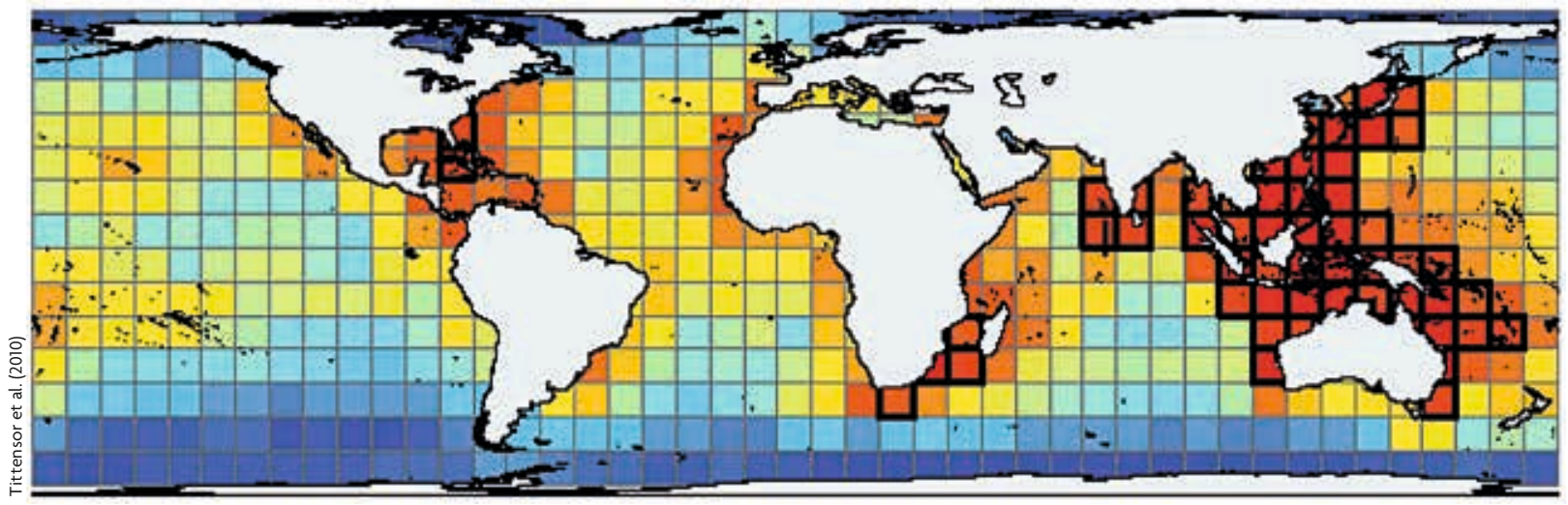

Figure 1. Global marine biodiversity pattern. Warmer color means higher biodiversity (therefore, more species).

because severe cooling in high latitudes made the latitudinal temperature gradient steeper (Yasuhara et al., 2012).

\section{CHANGING BIODIVERSITY HOTSPOTS}

Even within tropical oceans known as biodiverse regions, biodiversity is not the same in space or time. Certain areas have much more species than others. Species diversity varies not only with latitudes, as I discussed in the last section above, but also with longitudes. The Coral Triangle is such a place, characterized by highest marine biodiversity in the world (Figures 1 and 4) (Bellwood, Renema, \& Rosen, 2012). But even its diversity has changed over time.

\section{"LITTLE IS KNOWN ABOUT HOW MARINE BIODIVERSITY RESPONDS TO RAPID CHANGES IN CLIMATES AND ENVIRONMENTS OVER DECADES AND CENTURIES"}

Large forams (Figure 2), a type of benthic foraminifera with a large shell and symbiont algae, show direct evidence that the Coral Triangle has been changing regarding its biodiversity. It may not be surprising that the diversity in the Coral Triangle has been persistently high for the past 20 million years. But before that, biodiversity in this region was more modest. In the Eocene, for example, diversity was instead highest in the Tethys, the ancient Mediterranean Sea (Figure 4) (Renema et al., 2008; Yasuhara, Tittensor, et al., 2017).

The establishment of the Coral Triangle biodiversity hotspot at around 20 million years ago

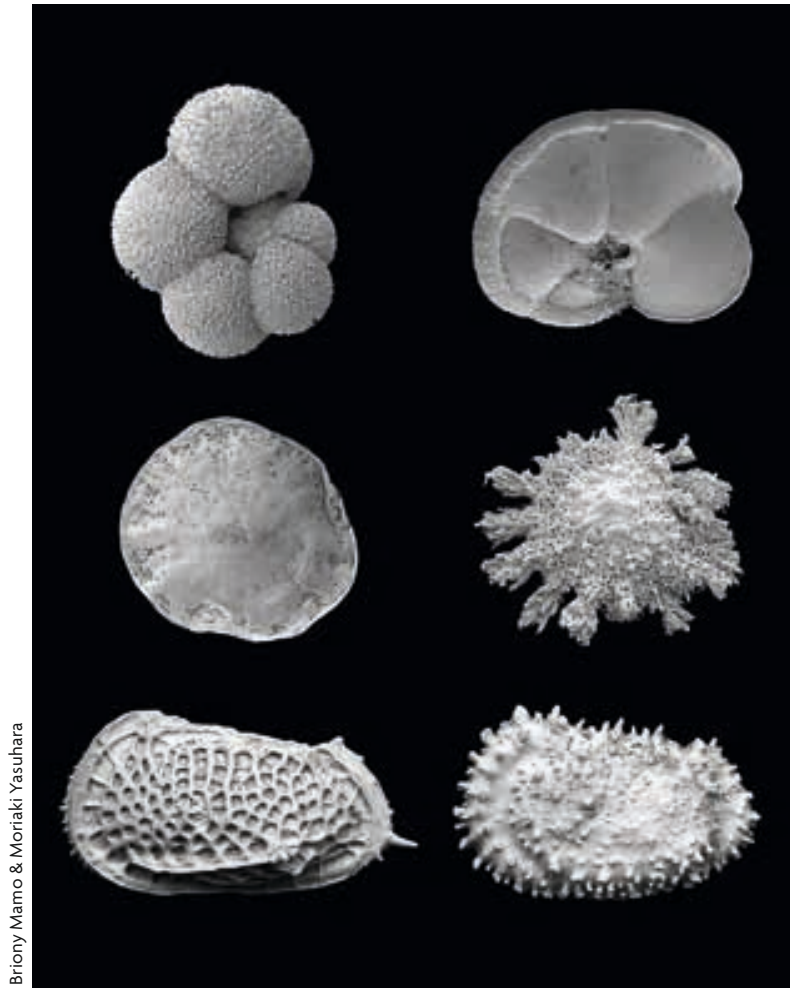

Figure 2. Scanning electron microscopy images of microfossils. Top row: planktonic foraminifera; mid row: large benthic foraminifera; bottom row: deep-sea benthic ostracods. Most of planktonic foraminifera and ostracods are smaller than or around $1 \mathrm{~mm}$ in size. Large benthic foraminifera tend to be larger, up to several centimeters in size. These images are not to scale.

"IT IS NOW INCREASINGLY IMPORTANT TO INTEGRATE BOTH BIOLOGICAL

\section{AND FOSSIL DATA TO BETTER}

UNDERSTAND OUR PLANET» 

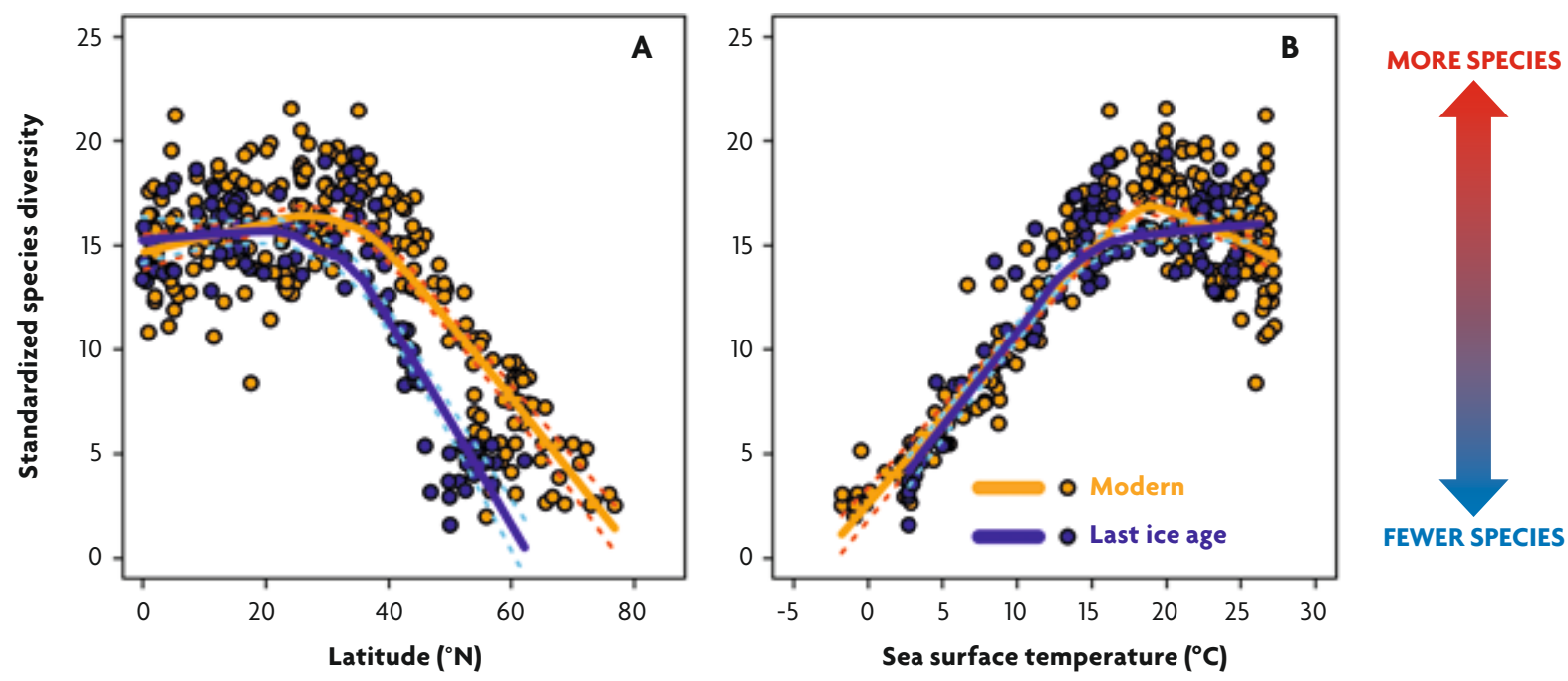

Figure 3. Latitudinal species diversity gradients (A) and temperature-diversity relationships (B) of planktonic foraminifera in the modern era and last ice age (20,000 years ago) oceans. The lines are smoothed curves of the scatter plots. The ice age latitudinal diversity gradient is much steeper than the present-day one (A). The relationship between temperature and diversity is surprisingly consistent between the present day and the last ice age (B). The reason why latitudinal diversity gradient was steeper during the last ice age is that severe cooling in high latitudes made the latitudinal temperature gradient steeper.

Modified from Yasuhara et al. (2012).

is also supported by fossils and molecular data of other organisms including ostracods, gastropods, and fishes (Renema et al., 2008; Yasuhara, Iwatani, et al., 2017). This origin of the Coral Triangle biodiversity hotspot is likely related to the collision of Australia with Pacific arcs and the Southeast Asian margin at around 23-25 million years ago that formed large, diverse, complicated, and dynamic shallow-marine habitats aiding biodiversity in this region (Renema et al., 2008; Yasuhara, Iwatani, et al., 2017; Yasuhara, Tittensor et al., 2017).

\section{CLIMATE AND DEEP-SEA BIODIVERSITY}

The deep sea is another ecosystem known to harbor numerous species (Ingels et al., 2016; Rex \& Etter, 2010). Climatic impact on deep-sea biodiversity is a topic that can be properly addressed only by paleontological records, especially those of microfossils, because, firstly, our monitoring of modern marine organisms is often not long enough to evaluate the effects of climatic changes occurring over periods of time longer than human lifespans (Yasuhara, Doi, Wei, Danovaro, \& Myhre, 2016), and, secondly, most deep-sea organisms, especially large ones, do not have mineralized structures (bivalves and gastropods have shells but their fossil abundance is too low in deep-sea sediments) and thus have virtually no fossil record. Sediments deposited in deep ocean floor are an ideal archive to study this topic, because they contain numerous microfossils and also excellent climatic records that can be reconstructed by various geochemical methods. Microfossils of small, but beautiful crustaceans (ostracods as the ones seen in Figure 2, which are generally $1 \mathrm{~mm}$ or smaller in size and very sensitive to environmental changes, with more than 20,000 living species estimated) show clear correlation with glacialinterglacial climatic changes (Cronin \& Raymo, 1997; Yasuhara \& Cronin, 2008; Yasuhara, Hunt, Cronin, \& Okahashi, 2009), with biodiversity higher in warmer periods and lower in ice ages (Figure 5) (Yasuhara et al., 2009). This temperature control of deep-sea biodiversity is well known over different time scales from the present day, through decades to hundreds of thousands of years (Yasuhara \& Danovaro, 2016).

\section{BRIDGING THE GAP}

Traditionally biology and paleontology have been studied separately by different research communities. 


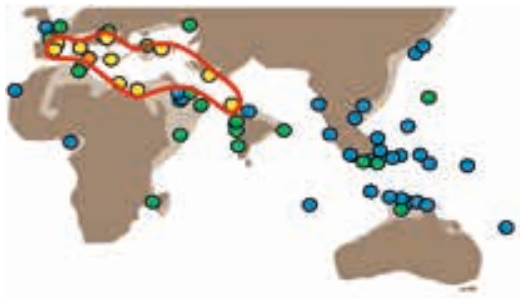

(A) Late Middle Eocene

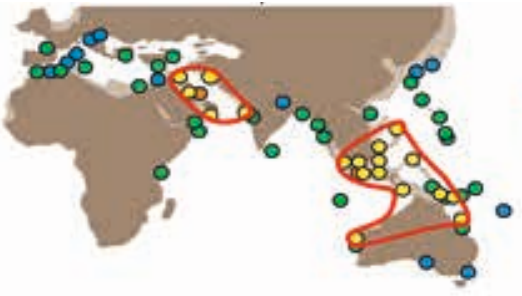

(B) Early Miocene

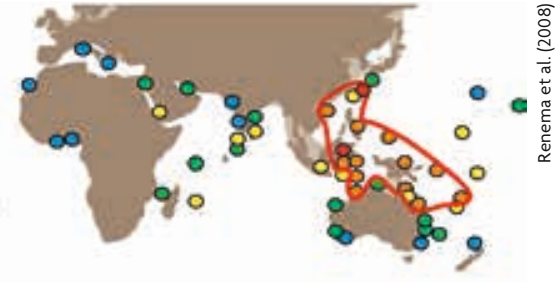

(C) Present day

Number of genera: $\bullet 1-4 \quad 0$ 5-8 $\circ 9-12 \quad 013-16 \quad \bullet>16$

Figure 4. Global diversity distribution of large benthic foraminiferal genera in (A) the late Middle Eocene (42-39 million years ago), (B) the Early Miocene (23-16 million years ago), and (C) the present day. We can observe how the hot spots of diversity (marked with red lines) have been changing. During the Eocene, the highest diversity was found in the Tethys Ocean (the ancient Mediterranean), while during the Early Miocene it was located in the Arabian Peninsula. The biodiversity hot spot of the coral triangle started to form in that era, about twenty million years ago, and still exists at the moment.

However, it is now increasingly important to integrate both biological and fossil data to better understand our planet and organisms living there (Yasuhara, Tittensor, et al., 2017). Our planet is rapidly changing from various human activities, and knowing past responses to similar changes is very important in allowing us to better prepare for the coming future. Thanks to their extraordinary fossil record, microfossils, although tiny, play a crucial role in meeting this challenge.

As a concluding remark, it is notable that little is known about how marine biodiversity responds to rapid changes in climates and environments over decades and centuries, which are important time scales relevant to ongoing and future human-induced changes such as global warming, deoxygenation, acidification, pollution, sea-level rise, and overfishing (Breitburg et al., 2018; Jackson et al., 2001; Mora et al., 2013). These time scales have been a «blind spot» between biological and paleoecological studies, that are too long for human observation and too short to resolve in ordinary fossil records. Exceptionally highly resolved microfossil records allow us to address these time scales and, indeed, recent studies using exceptional microfossil records have been showing, for example, that deep-sea biodiversity has been sensitive to abrupt climate changes on these time scales (Yasuhara et al., 2016; Yasuhara, Cronin, deMenocal, Okahashi, \& Linsley, 2008; Yasuhara, Okahashi, Cronin, Rasmussen, \& Hunt, 2014). The microfossil records showed clear footprints of well-known abrupt climate change events of Heinrich I (17,000-14,600 years ago) and
Younger Dryas (12,900-11,700 years ago) on deepsea biodiversity (Figure 6) (Yasuhara et al., 2014). Statistical modeling indicated that these diversity changes were most likely caused by regional deepwater warming during these abrupt climate change events (Yasuhara et al., 2014). These abrupt climate changes may have affected not only biodiversity but also function of deep-sea ecosystem (Yasuhara et al., 2016). Microfossils help our better understanding of past, present, and future ecosystems by bridging the gap between biological and paleontological time-scales (Mesquita-Joanes, Smith, \& Viehberg, 2012; Yasuhara, Tittensor, et al., 2017).

\section{REFERENCES}

Bellwood, D. R., Renema, W., \& Rosen, B. R. (2012). Biodiversity hotspots, evolution and coral reef biogeography: A review. In D. J. Gower, K. G. Johnson, J. E. Richardson, B. R. Rosen, L. Rüber, \& S. T. Williams (Eds.), Biotic evolution and environmental change in Southeast Asia (pp. 216-245). Cambridge: Cambridge University Press.

Breitburg, D., Levin, L. A., Oschlies, A., Grégoire, M., Chavez, F. P., Conley, D. J., ... Zhang, J. (2018). Declining oxygen in the global ocean and coastal waters. Science, 359(6371), eaam7240. doi: 10.1126/science. $\operatorname{aam} 7240$

Cronin, T. M., \& Raymo, M. E. (1997). Orbital forcing of deep-sea benthic species diversity. Nature, 385, 624-627. doi: 10.1038/385624a0

Hillebrand, H. (2004). Strength, slope and variability of marine latitudinal gradients. Marine Ecology Progress Series, 273, 251-267. doi: 10.3354/ meps273251

Ingels, J., Clark, M. R., Vecchione, M., Perez, J. A. A., Levin, L. A., Priede, I. G., ... Van Gaever, S. (2016). Chapter 36F. Open Ocean Deep Sea. In L. Inniss \& A. Simcock (Eds.), First global integrated marine assessment. World ocean assessment I. New York, NY: United Nations. Jackson, J. B. C., Kirby, M. X., Berger, W. H., Bjorndal, K. A., Botsford, L. W., Bourque, B. J., ... Warner, R. R. (2001). Historical overfishing and the recent collapse of coastal ecosystems. Science, 293(5530), 629-638. doi: 10.1126/science.1059199

Mesquita-Joanes, F., Smith, A. J., \& Viehberg, F. A. (2012). The ecology of Ostracoda across levels of biological organisation from individual to 


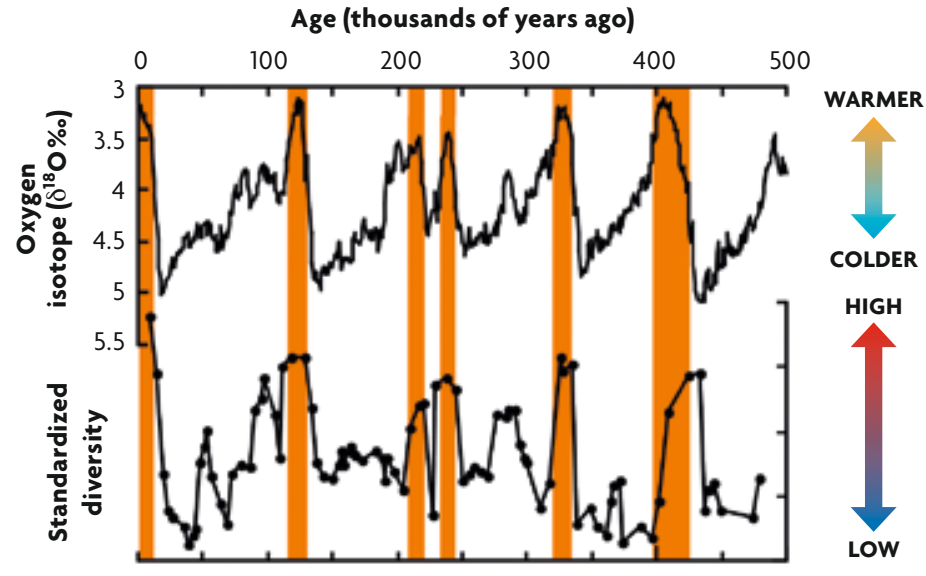

Figure 5. Comparison between global climate and deep-sea ostracod species diversity changes for the last 500,000 years. The oxygen isotope curve represents global climate changes, and the lower isotope values indicate warmer intervals. Major warm climate peaks are highlighted by orange bars. It can be observed that the biodiversity of these ostracods is higher at warmer periods and lower during ice ages.

Modified from Yasuhara et al. (2009).

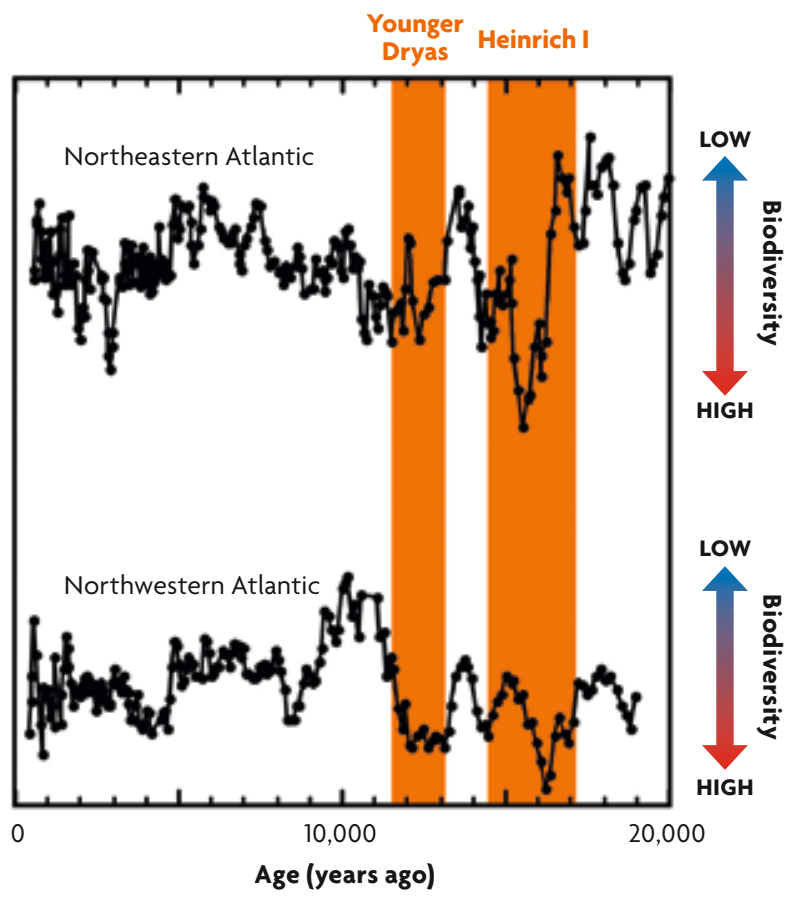

Figure 6. Deep-sea biodiversity changes in the northeastern and northwestern Atlantic Ocean for the last 20,000 years. Fossil records of these $50,000 \mathrm{~km}$ distant sites show synchronous, rapid biodiversity increases during the rapid climate change events of Younger Dryas and Heinrich I (highlighted by orange). Higher biodiversity means more species in a sample.

Modified from Yasuhara et al. (2014). ecosystem: A review of recent developments and future potential. In D. J. Horne, J. Holmes, J. Rodriguez-Lazaro, \& F. A. Viehberg (Eds.), Ostracoda as proxies for Quaternary climate change (pp. 15-35). Amsterdam: Elsevier.

Mora, C., Wei, C. L., Rollo, A., Amaro, T., Baco, A. R., Billett, D., .. Yasuhara, M. (2013). Biotic and human vulnerability to projected changes in ocean biogeochemistry over the 21st century. PLoS Biology, 11(10), e1001682. doi: 10.1371/journal.pbio.1001682 Renema, W., Bellwood, D. R., Braga, J. C., Bromfield, K., Hall, R., Johnson, K. G., ... Pandolfi, J. M. (2008). Hopping hotspots: Global shifts in marine biodiversity. Science, 321(5889), 654-657. doi: $10.1126 /$ science. 1155674

Rex, M. A., \& Etter, R. J. (2010). Deep-sea biodiversity: Pattern and scale. Cambridge: Harvard University Press.

Tittensor, D. P., Mora, C., Jetz, W., Lotze, H. K., Ricard, D., Berghe, E. V., \& Worm, B. (2010). Global patterns and predictors of marine biodiversity across taxa. Nature, 466, 1098-1101. doi: 10.1038/ nature09329

Yasuhara, M., \& Cronin, T. M. (2008). Climatic influences on deepsea ostracode (Crustacea) diversity for the last three million years. Ecology, 89(11), S53-S65. doi: 10.1890/07-1021.7

Yasuhara, M., Cronin, T. M., DeMenocal, P. B., Okahashi, H., \& Linsley, B. K. (2008). Abrupt climate change and collapse of deep-sea ecosystems. Proceedings of the National Academy of Sciences of the United States of America, 105(5), 1556-1560. doi: 10.1073/pnas.0705486105

Yasuhara, M., \& Danovaro, R. (2016). Temperature impacts on deep-sea biodiversity. Biological Reviews, 91(2), 275-287. doi: 10.1111/brv.12169

Yasuhara, M., Doi, H., Wei, C. L., Danovaro, R., \& Myhre, S. E. (2016). Biodiversity-ecosystem functioning relationships in longterm time series and palaeoecological records: Deep sea as a test bed. Philosophical Transactions of the Royal Society B, 371(1694). doi: 10.1098/rstb.2015.0282

Yasuhara, M., Hunt, G., Cronin, T. M., \& Okahashi, H. (2009). Temporal latitudinal-gradient dynamics and tropical instability of deep-sea species diversity. Proceedings of the National Academy of Sciences of the United States of America, 106(51), 21717-21720. doi: 10.1073/pnas.0910935106

Yasuhara, M., Hunt, G., Dowsett, H. J., Robinson, M. M., \& Stoll, D. K. (2012). Latitudinal species diversity gradient of marine zooplankton for the last three million years. Ecology Letters, 15(10), 1174-1179. doi: 10.1111/j.1461-0248.2012.01828.x

Yasuhara, M., Iwatani, H., Hunt, G., Okahashi, H., Kase, T., Hayashi, H., ... Renema, W. (2017). Cenozoic dynamics of shallow-marine biodiversity in the Western Pacific. Journal of Biogeography, 44(3), 567-578. doi: 10.1111/jbi.12880

Yasuhara, M., Okahashi, H., Cronin, T. M., Rasmussen, T. L., \& Hunt, G. (2014). Response of deep-sea biodiversity to abrupt deglacial and Holocene climate changes in the North Atlantic Ocean. Global Ecology and Biogeography, 23(9), 957-967. doi: 10.1111/geb.12178

Yasuhara, M., Tittensor, D. P., Hillebrand, H., \& Worm, B. (2017). Combining marine macroecology and palaeoecology in understanding biodiversity: Microfossils as a model. Biological Reviews, 92(1), 199-215. doi: 10.1111/brv.12223

Moriaki Yasuhara. Associate professor in the School of Biological Sciences and the Swire Institute of Marine Science at the University of Hong Kong (China). He has broad interests in marine palaeoecology and macroecology, especially those using highly resolved micropalaeontological records. His recent research has focused on the spatiotemporal dynamics of large-scale biodiversity patterns, the climatic and temperature impacts on species diversity, and the controlling factor(s) of biodiversity patterns/change in shallow-marine, deep sea and pelagic ecosystems. He is also interested in microfossil-based conservation palaeobiology as well as palaeontology of the Ostracoda in general. $₫$ yasuhara@hku.hk 